СОРБЦИОННО-ФОТОМЕТРИЧЕСКОЕ И ТЕСТОПРЕДЕЛЕНИЕ ОБЩЕГО СОДЕРЖАНИЯ ЖЕЛЕЗА В ПРИРОДНЫХ ВОДАХ С ИСПОЛЬЗОВАНИЕМ СОРБЕНТОВ НА ОСНОВЕ ОКСИДА ЦИРКОНИЯ, МОДИФИЦИРОВАННОГО ПОЛИГЕКСАМЕТИЛЕНГУАНИДИНОМ, ФЕРРОЗИНОМ И ФЕРЕНОМ C

\author{
С.Л. Дидух, А.Н. Мухина, В.Н. Лосев \\ Научно-исследовательский инженерный центр «Кристалл» \\ Сибирского федерального университета, \\ Российская Федерация, 660041, Красноярск, пр. Свободный, 79 \\ losevvn@gmail.com
}

Поступила в редакцию 23 сентября 2014 г., после доработки - 14 ноября 2014 г.

Получены сорбенты на основе оксида циркония, последовательно модифицированного полигексаметиленгуанидином, феррозином и ференом С. Найдены оптимальные условия модифицирования аминированной поверхности оксида циркония феррозином и ференом С. Сорбционная емкость по отношению к органическим реагентам составляет 25 мкM/г для фреррозина и 5 мкM/г для ферена С. Синтезированные сорбенты количественно извлекают железо(II) из растворов с $\mathrm{pH}=2.5-7.0$. При сорбции на поверхности сорбентов образуются интенсивно окрашенные комплексы железа(II), имеющие в спектре диффрузного отражения широкую полосу с максимумом при 560 и 600 нм соответственно для сорбентов с функциональными группами феррозина и ферена С. Максимальная интенсивность окраски развивается в течение 20 мин при $\mathrm{pH}=2.5-5.0$. Образование окрашенных комплексов на поверхности сорбента использовано при разработке методик сорбционно-фотометрического и тест-определения железа(II). Градуировочные графики линейны в диапазоне от 0.1 до 4.0 мкг/0.1 г. Предел обнаружения железа(II) сорбционно-фотометрическим методом, рассчитанный по 3s-критерию, равен 0.006 мкг/0.1 г и 0.015 мкг/0.1 г для сорбентов с функциональными группами феррозина и ферена С, соответственно. Методики использованы при определении общего содержания железа в природных водах. Правильность методик подтверждена атомно-эмиссионным методом с индуктивно связанной плазмой.

Ключевые слова: сорбционное концентрирование, модифицированный оксид циркония, феррозин, фререн C, железо(II), сорбционно-фотометрическое определение, тест-системы.

Дидух Светлана Леонидовна, кандидат химических наук, доцент, научный сотрудник, Сибирский федеральный университет.

Область научных интересов: сорбционное концентрирование элементов сорбентами на основе неорганических оксидов, сорбционно-спектроскопические методы определения элементов, химические тест-методы анализа.

Автор 39 научных работ.

Мухина Александра Николаевна, аспирант Сибирского федерального университета.

Область научных интересов: сорбционное концентрирование элементов сорбентами на основе неорганических оксидов, сорбционно-фотометрическое определение элементов.

Автор 8 научных работ.

Лосев Владимир Николаевич, доктор химических наук, профессор, старший научный сотрудник, Сибирский федеральный университет.

Область научных интересов: сорбенты на основе неорганических оксидов, сорбционное концентрирование элементов, сорбционно-спектроскопические методы определения элементов.

Автор 300 научных работ. 


\section{Введение}

Железо в природных водах находится в виде двух- и трехзарядных ионов. Железо(II) в результате химического (кислородом воздуха) и биохимического (при участии железобактерий) окисления переходит в железо(III), которое в природных водах находится в виде соединений с растворенными неорганическими и органическими соединениями [1].

Для фротометрического определения используются интенсивно окрашенные комплексные соединения $\mathrm{Fe}^{2+}$ или $\mathrm{Fe}^{3+}$ с органическими реагентами [2]. Наиболее распространенными реагентами для определения $\mathrm{Fe}(\mathrm{III})$ являются сульфосалициловая кислота [2, 3] и тайрон [4, 5]. Однако по своей чувствительности методики с их использованием уступают фотометрическим методикам определения железа(II) с использованием $\mathrm{N}$-гетероциклических оснований: 1,10-френантролина [6, 7], 2,2'-дипиридила $[8,9]$ и их производных. Относительно новыми фотометрическими реагентами (известны с 1970 г.) для определения железа(II) являются производные триазина: 3-(2-пиридил)-5,6-дифенил-1,2,4-триазин и 3-(2-пиридил)-5,6-ди(2-фурил)-1,2,4-триазин и их сульфопроизводные [10], имеющие такую же функционально-аналитическую группу, как 1,10-френантролин и 2,2'-дипиридил. Сульфопроизводные пиридилтриазинов, в отличие от их несульфированных аналогов, хорошо растворимы в воде. Железо(II) взаимодействует с атомами азота в гетероциклах пиридилтриазина с образованием интенсивно окрашенных комплексных соединений.

Фотометрические методики определения железа(II) с использованием пиридилтриазинов характеризуются более низкими пределами обнаружения по сравнению с методиками, основанными на использовании 1,10-френантролина и 2,2'-дипиридила.

Для повышения чувствительности фотометрических методик их комбинируют с предварительным концентрированием: экстракцией в органические среды или сорбцией на твердых матрицах.
Авторами работы [11] предложена методика экстракционно-спектрофотометрического определения железа(II) с 3-(2-пиридил)-5,6-дифенил-1,2,4триазином, водный комплекс которого экстрагируют в 1,2-дихлорэтан. Микроколичества железа(II) определяют в виде комплекса с 3-(4-фенил-2-пиридил)5,6-дифенил-1,2,4-триазином и тетрафенилборатом адсорбированного на кристаллическом нафталине [12]. Для концентрирования следовых количеств железа(II) в виде комплекса с 3-(2-пиридил)5,6-дифенил-1,2,4-триазином и его последующего определения предложено использовать нитроцеллюлозный мембранный фильтр [13].

Для сорбционного концентрирования элементов перспективны сорбенты на основе неорганических оксидов [14], отличающихся от полимерных сорбентов на органической основе отсутствием явления набухания и собственной окраски [15]. Неорганические оксиды обладают достаточной механической и химической устойчивостью, высокой удельной поверхностью, используются для концентрирования ионов металлов или их комплексов из растворов или в качестве матрицы для химического или нековалентного модифицирования органическими реагентами с целью получения новых типов сорбентов.

Закрепление 3-(2-пиридил)-5,6-дифенил-1,2,4триазин-4',4"-дисульфокислоты (Феррозин, Ferrozine) и 3-(2-пиридил)-5,6-ди(2-фурил)-1,2,4-триазин5,5"-дисульфокислоты (Ферен C, Ferene S) (табл. 1) непосредственно на поверхности оксида циркония из водных растворов затруднено из-за взаимного отталкивания сульфогрупп реагентов и поверхностных гидроксильных групп. Ранее нами [16] для закрепления на поверхности неорганических оксидов одного из селективных реагентов на железо(II) - 4,7-дифенил-1,10-френатролиндисульфокислота предложен способ предварительного модифицирования поверхности полигексаметиленгуанидином. Закрепленный полигексаметиленгуанидин, являющийся сильным основанием ( $\left.K_{\mathrm{a}} \sim 13\right)$, создает на

Таблица 1

Органические реагенты - модификаторы

\begin{tabular}{|c|c|c|c|}
\hline Реагент и его обозначение & Формула \\
3-(2-пиридил)-5,6-дифенил-1,2,4-триазин-4',4"- \\
дисульфокислота (Феррозин, Ferrozine)
\end{tabular}


поверхности неорганических оксидов положительно заряженный полимерный слой, с которым происходит взаимодействие сульфогрупп реагентов.

В настоящей работе исследованы сорбционные свойства оксида циркония, последовательно модифицированного полигексаметиленгуанидином, феррозином или ференом С, по отношению к $\mathrm{Fe}(\mathrm{II})$ и разработаны методики сорбционно-фотометрического и тест-определения общего содержания железа в виде железа(II) в природных водах.

\section{Экспериментальная часть}

Реагенты и растворы. В качестве основы для синтеза сорбентов использовали дисперсный оксид циркония квалификации «х.ч.» (средний размер частиц 50 мкм, удельная поверхность 14 м²/г). В качестве модификаторов поверхности использовали 5 \%-ный раствор полигексаметиленгуанидина гидрохлорида (ПГМГ), 1·10-3 М растворы фреррозина и ферена С.

Исходный раствор железа(II) с концентрацией 100 мг/л готовили растворением навески соли $\mathrm{FeSO}_{4} \cdot 7 \mathrm{H}_{2} \mathrm{O}$ в $0.1 \mathrm{M} \mathrm{H}_{2} \mathrm{SO}_{4}$ для предотвращения гидролиза. Точную концентрацию железа устанавливали комплексонометрическим титрованием ЭДТА сульфосалициловой кислотой после окисления железа(II) до железа(III) пероксидом водорода [17]. Рабочие растворы готовили в день проведения эксперимента разбавлением исходного раствора деионизованной водой.

Для восстановления железа(III) до железа(II) использовали 0.1 М раствор солянокислого гидроксиламина в деионизованной воде.

Растворы $\mathrm{H}_{2} \mathrm{SO}_{4}, \mathrm{HNO}_{3}, \mathrm{NaOH}$ имели квалификацию «ос.ч.».

Аппаратура. Оптическую плотность растворов измеряли на спектрофотометре Cary 100 (Varian, США). Иономер Seveneasy (Mettler-Toledo, Испания) использовали для измерения $\mathrm{pH}$ растворов.

Содержание железа в растворах определяли по анализу водной фазы атомно-эмиссионным с индуктивно связанной плазмой методом на спектрометре Optima 5300 (Perkin-Elmer, США). Коэффициент диффузного отражения сорбентов измеряли на спектрофотоколориметре «Пульсар» (НПО Химавтоматика, Россия).

Методика модифицирования поверхности оксида циркония. Оксид циркония выдерживали в растворе при рН = 10 в течение 2 часов для активации поверхности, затем промывали деионизованной водой до $\mathrm{pH}=7$. К навеске (10 г) оксида циркония при перемешивании добавляли 100 мл 5 \%-ного раствора ПГМГ. Раствор сливали, сорбент промывали деионизованной водой и высушивали при температуре $70^{\circ} \mathrm{C}$. Далее к полученному сорбенту (ZrO твора фреррозина или ферена C, перемешивали 10 мин. Полученный сорбент ( $\mathrm{ZrO}_{2}$-ПГМГ-Ferrozine, $\mathrm{ZrO}_{2}$-ПГМГ-Ferene S) дважды промывали деиони- зованной водой, отделяли от раствора декантацией и высушивали на воздухе.

Контроль за распределением реагентов осуществляли по анализу водной фазы фотометрическим методом по характеристичным полосам поглощения реагентов 283 нм (феррозин) и 303 нм (ферен C).

Методика изучения сорбции железа(II). При изучении сорбции железа(II) в статическом режиме в градуированную пробирку с притертой пробкой емкостью 20 мл вводили раствор железа(II) необходимой концентрации, добавляли 1 мл 0.1 М раствора гидроксиламина для предотвращения окисления железа(II) до железа(III) кислородом воздуха, $\mathrm{NaOH}$ для создания необходимого значения $\mathrm{pH}$, деионизованную воду до 10 мл. Вносили 0.1 г сорбента $\mathrm{ZrO}_{2}$-ПГМГ-Ferrozine или $\mathrm{ZrO}_{2}$-ПГМГ-Ferene $\mathrm{S}$ и перемешивали в течение 20 мин. Сорбент отделяли от раствора декантацией, переносили во фрторопластовую кювету, убирали излишки воды фильтровальной бумагой и регистрировали коэффициент диффузного отражения $(R)$. При таком способе удаления излишков воды значения $R$ постоянны, в пределах 5 \%-ной погрешности измерения, в течение 20 мин. Спектры диффузного отражения (СДО) приведены в координатах: функция Гуревича-Кубелки-Мунка $\left(F(R)=(1-R)^{2} / 2 R\right)$ - длина волны, нм.

\section{Результаты и их обсуждение}

Закрепление органических реагентов на поверхности оксида циркония, модифицированного полигексаметиленгуанидином. Оксид циркония, модифицированный ПГМГ, количественно ( $\geq 99$ \%) извлекает феррозин и ферен С из водных растворов в диапазоне $\mathrm{pH}=3.0-7.5$.

Сорбционная емкость $\mathrm{ZrO}_{2}$-ПГМГ по отношению к органическим реагентам, определенная из горизонтальных участков изотерм сорбции, составляет 25 мкМ/г для феррозина и 5 мкМ/г для фререна С (рис. 1). Такое различие в сорбционных емкостях по органическим реагентам при практически

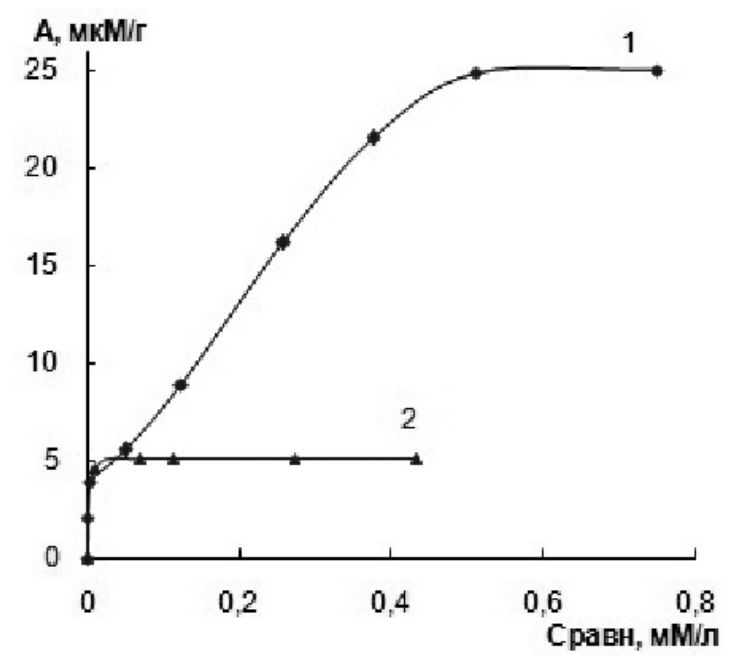

Рис. 1. Изотермы сорбции феррозина (1) и ферена С (2) на $\mathrm{ZrO}_{2}$-ПГМГ: 0.1 г сорбента; $V=10$ мл; $\mathrm{pH}=5.5$ 


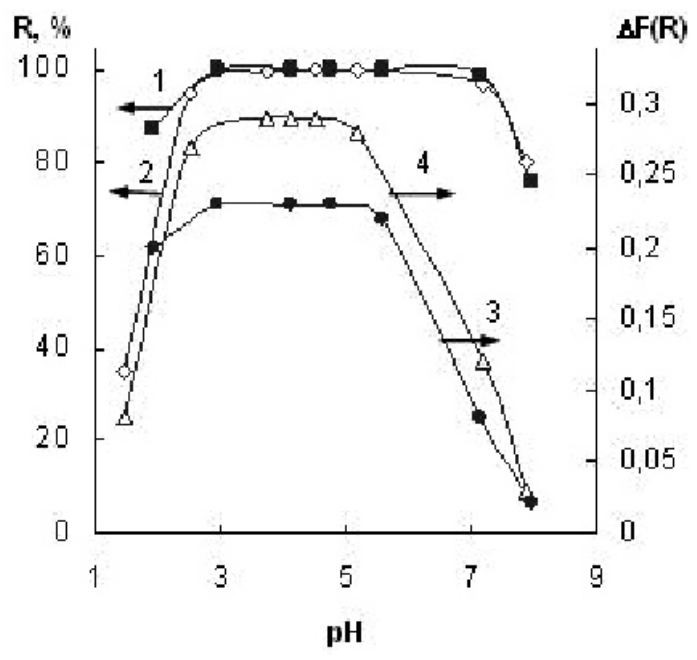

Рис. 2. Степень извлечения железа(II) $(1,2)$ и зависимости $\Delta F(R)$ поверхностного комплекса железа(II) $(3,4)$ от $\mathrm{pH}$ на $\mathrm{ZrO}_{2}$-ПГМГ-Ferrozine $(1,3)$ и $\mathrm{ZrO}_{2}$-ПГМГ-Ferene S (2, 4): $C_{\mathrm{Fe}}=0.3$ мкг/0.1 г сорбента; $V=10$ мл; $0.01 \mathrm{M} \mathrm{NH}_{2} \mathrm{OH}$

идентичной структуре (табл. 1) и площади молекул может быть связано с их различным пространственным расположением на поверхности сорбента $\mathrm{ZrO}_{2}$-ПГМГ. Вероятно, молекулы феррозина располагаются перпендикулярно поверхности сорбента, закрепляясь за счет электростатического взаимодействия между сульфогруппами реагента и протонированными аминогруппами ПГМГ, а молекулы ферена С располагаются параллельно поверхности, закрепляясь как за счет электростатического взаимодействия, так и за счет образования водородной связи между кислородом фурильного заместителя и аминогруппами ПГМГ.

Устойчивость закрепления органических реагентов на поверхности $\mathrm{ZrO}_{2}$-ПГМГ изучали обработкой сорбентов растворами азотной кислоты и хлорида натрия различных концентраций. Закрепленные фреррозин и ферен С на поверхности оксида циркония, модифицированного полигексаме- тиленгуанидином, устойчивы к воздействию слабо кислых и низко солевых растворов. Количественная степень десорбции органических реагентов достигается при обработке сорбентов $2 \mathrm{M} \mathrm{HNO}_{3}$ или $1 \mathrm{M} \mathrm{NaCl}$.

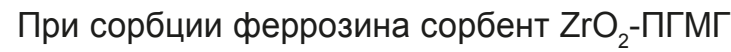
остается бесцветным, а при сорбции ферена C поверхность сорбента приобретает светло-желтый цвет.

Сорбционное концентрирование железа(II). Сорбенты $\mathrm{ZrO}_{2}$-ПГМГ-Ferrozine и $\mathrm{ZrO}_{2}$-ПГМГ-Ferene S количественно (степень извлечения 98-99 \%) извлекают железо(II) из растворов в диапазоне $\mathrm{pH}$ от 2.5 до 7.0 (рис. 2, крив. 1 и 2). Время установления сорбционного равновесия не зависит от природы реагента и не превышает 10 мин.

При сорбции железа(II) поверхность сорбента $\mathrm{ZrO}_{2}$-ПГМГ-Ferrozine окрашивается в сиреневый цвет, $\mathrm{ZrO}_{2}$-ПГМГ-Ferene S - в синий цвет. Спектры диффузного отражения поверхностных комплексов $\mathrm{Fe}(\mathrm{II})$ представляют собой широкие полосы с максимумами при 560 нм на $\mathrm{ZrO}_{2}$-ПГМГ-Ferrozine и 600 нм на $\mathrm{ZrO}_{2}$-ПГМГ-Ferene $\mathrm{S}$ (рис. 3). Время контакта фаз, необходимое для достижения максимальной интенсивности окраски, составляет 20 мин. Максимальная интенсивность окраски поверхностных комплексов железа(II) постоянна в диапазоне $\mathrm{pH}$ от 2.5 до 5.0 и не зависит от природы органического реагента (рис. 2, крив. 3 и 4).

Сорбционно-фотометрическое определение железа(II) с использованием сорбентов $\mathrm{ZrO}_{2}$ ПГМГ-Ferrozine и $\mathrm{ZrO}_{2}$-ПГМГ-Ferene S. Образование интенсивно окрашенных комплексов железа(II) на поверхности оксида циркония, последовательно модифицированного ПГМГ, фреррозином или ференом C, положено в основу разработки методик сорбционно-фотометрического определения железа(II) в фазе сорбентов с использованием спектроскопии диффузного отражения. При увеличении содержания $\mathrm{Fe}(\mathrm{II})$ на поверхности сорбентов $\mathrm{ZrO}_{2}$-ПГМГFerrozine и $\mathrm{ZrO}_{2}$-ПГМГ-Ferene S пропорционально
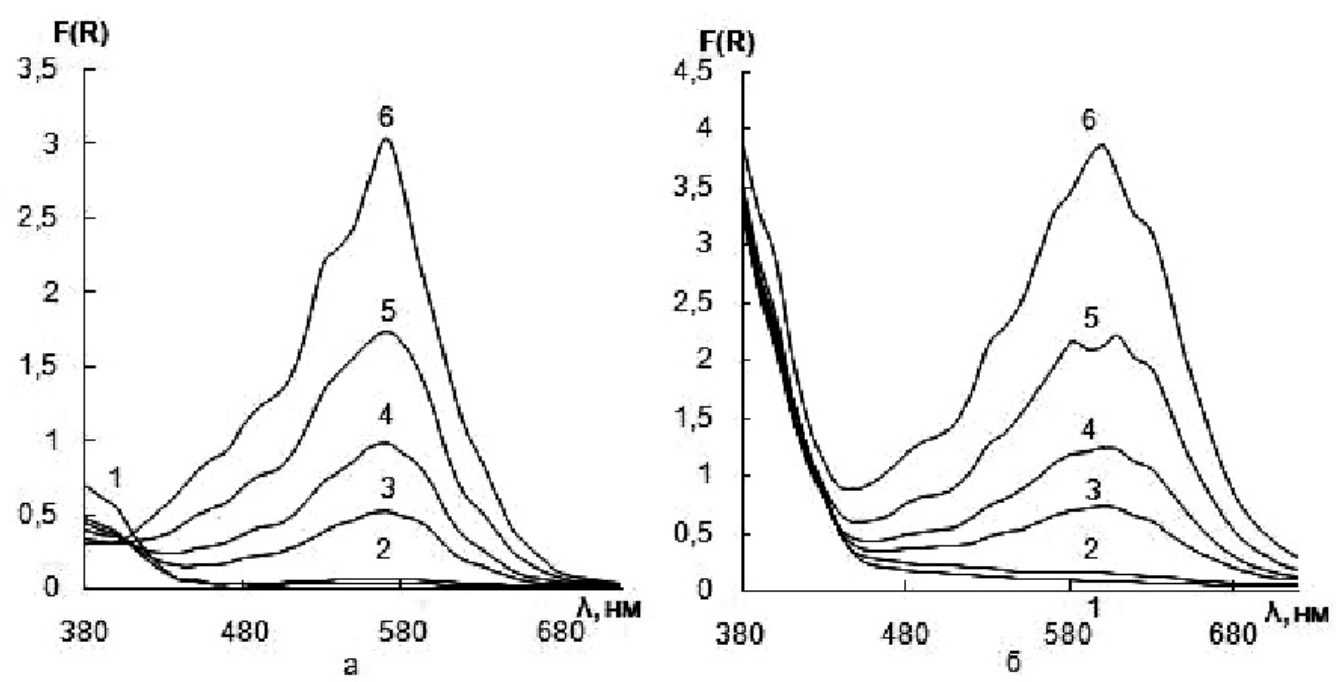

Рис. 3. Спектры диффрузного отражения комплекса железа(II) на поверхности $\mathrm{ZrO}_{2}$-ПГМГ-Ferrozine (a) и $\mathrm{ZrO}_{2}$-ПГМГFerene S (б): $C_{\mathrm{Fe}}$ мкг/0.1 г сорбента: 0 (1), 0.1 (2), 0.5 (3), 1 (4), 2 (5), 4 (6); pH = 3; V = 10 мл; $0.01 \mathrm{M} \mathrm{NH}_{2} \mathrm{OH}$ 
возрастает интенсивность полос в СДО с максимумами при 560 и 600 нм соответственно (рис. 3).

Построение градуировочных графиков. В ряд градуированных пробирок вводят от 0.1 до 10 мкг железа(II) в виде раствора в $0.1 \mathrm{M} \mathrm{H}_{2} \mathrm{SO}_{4}, 1$ мл $0.1 \mathrm{M}$ раствора солянокислого гидроксиламина для восстановления $\mathrm{Fe}(\mathrm{III})$ до $\mathrm{Fe}(\mathrm{II}), \mathrm{NaOH}$ до $\mathrm{pH}=3$ и деионизованную воду до объема 10 мл. Вносят 0.1 г сорбента ZrO интенсивно перемешивают 20 мин. Сорбент отделяют от раствора декантацией, переносят во фрторопластовую кювету, убирают излишки воды фильтровальной бумагой и измеряют коэффрициент дифрфузного отражения при 560 нм для $\mathrm{ZrO}_{2}-$ ПГМГ-Ferrozine и 600 нм для $\mathrm{ZrO}_{2}$-ПГМГ-Ferene S. Градуировочные графики, построенные по 10 точкам в координатах $\Delta F(R)-C_{\mathrm{Fe}}$, мкг на 0.1 г сорбента, описываются уравнениями:

$\Delta F(R)=(0.78 \pm 0.02) \cdot C_{\mathrm{Fe}}\left(r^{2}=0.992\right)$ для $\mathrm{ZrO}_{2}$-ПГМГ-Ferrozine

и $\Delta F(R)=(0.97 \pm 0.03) \cdot C_{\mathrm{Fe}}\left(r^{2}=0.989\right)$ для $\mathrm{ZrO}_{2}-$ ПГМГ-Ferene $\mathrm{S}$.

Линейность градуировочных графиков сохраняется в диапазоне 0.1 - 4.0 мкг железа(II) на 0.1 г сорбента, что при сорбции из 10 мл раствора соответствует концентрации железа(II) в растворе 0.01-0.4 мг/л. Предел обнаружения железа, рассчитанный по 3s-критерию, равен 0.006 мкг/0.1г $\mathrm{ZrO}_{2}$-ПГМГ-

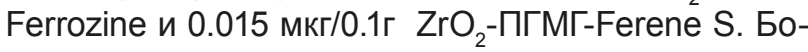
лее высокий предел обнаружения железа(II) при использовании сорбента с функциональными группами ферен C, несмотря на более высокий коэфрфициент чувствительности градуировочного графика, обусловлен желтой окраской сорбента. Относительное стандартное отклонение при определении более 0.1 мкг железа(II) на 0.1 г сорбента не превышает 0.07 .

Для изучения селективности сорбционнофоотометрического определения железа(II) создавали бинарные системы, содержащие 0.05 мкг/мл железа(II) и от 0.05 до 50 мкг/мл других ионов металлов и анионов. Определению 0.5 мкг $\mathrm{Fe}(\mathrm{II}) \mathrm{Ha}$ 0.1 г сорбента при $\mathrm{pH}=3$ не мешают (в кратных количествах): $\mathrm{Na}^{+}, \mathrm{K}^{+}, \mathrm{Ca}^{2+}, \mathrm{Mg}^{2+}, \mathrm{Sr}^{2+}, \mathrm{Al}^{3+}, \mathrm{Pb}^{2+}, \mathrm{Cd}^{2+}$, $\mathrm{Mn}^{2+}\left(10^{3}\right), \mathrm{Zn}^{2+}\left(10^{2}\right), \mathrm{Ni}^{2+}(5) ;$ солевой фон по $\mathrm{NaCl}$ или $\mathrm{Na}_{2} \mathrm{SO}_{4}$ до 50 г/л. Наибольшее влияние на опре- деление железа(II) при кратных соотношениях оказывает $\mathrm{Cu}(\mathrm{I})$. Для маскирования меди(I) использовали раствор тиомочевины. В присутствии 2 \%-ной тиомочевины определению железа(II) не мешают 10-кратные количества меди(I).

Разработанные сорбционно-фоотометрические методики использованы при определении общего содержания железа в виде железа(II) в природных речных водах.

Методика определения общего содержания железа в природных водах. К 100 мл природной воды добавляют конц. $\mathrm{HNO}_{3}$ до $\mathrm{pH}=1$, нагревают до кипения и кипятят в течение 30 мин для разрушения органических соединений. В результате обработки проб воды азотной кислотой для разрушения органических соединений происходит окисление железа(II) до железа(III). Реагенты феррозин и ферен С образуют комплексы только с железом(II), поэтому в дальнейшем Fe(III) восстанавливали до $\mathrm{Fe}(\mathrm{II})$ гидроксиламином.

В градуированные пробирки с притертыми пробками емкостью 20 мл вводят 8 мл природной воды, 1 мл 0.1 М раствора солянокислого гидроксиламина, $\mathrm{NaOH}$ до $\mathrm{pH}=3$ и деионизованную воду до 10 мл. Вносят 0.1 г сорбента и перемешивают 20 мин. Сорбент отделяют от раствора декантацией, переносят во фрторопластовую кювету, убирают излишки воды фильтровальной бумагой и измеряют коэфрфициент дифффузного отражения при 560 нм для $\mathrm{ZrO}_{2}$-ПГМГ-Ferrozine и 600 нм для $\mathrm{ZrO}_{2}$ ПГМГ-Ferene S. Содержание железа(II) находят по градуировочному графику, построенному в аналогичных условиях.

Результаты определения общего содержания железа в фрорме $\mathrm{Fe}(\mathrm{II})$ в природных речных водах приведены в табл. 2. Правильность результатов подтверждена атомно-эмиссионным методом с индуктивно связанной плазмой (АЭС-ИСП). Как видно из таблицы, разработанные методики сорбционно-фротометрического определения железа с использованием спектроскопии дифффузного отражения (СФ-СДО) позволяют получать правильные и воспроизводимые результаты.

Тест-методики определения железа(II) с использованием сорбентов $\mathrm{ZrO}_{2}$-ПГМГ-Ferrozine и $\mathrm{ZrO}_{2}$-ПГМГ-Ferene S. Образование интенсивно окрашенных комплексов железа(II) с фреррозином и фе-

Таблица 2

Результаты определения железа(II) в природных водах (V=10 мл, 0.1 г сорбента, $\mathrm{pH}=3$ )

\begin{tabular}{|c|c|c|c|c|}
\hline \multirow{2}{*}{$\begin{array}{c}\text { Название } \\
\text { реки }\end{array}$} & \multirow[t]{2}{*}{ Сорбент } & \multicolumn{3}{|c|}{ Найдено железо, мг/л } \\
\hline & & $\begin{array}{c}\text { АЭС-ИСП } \\
(n=5, P=0.95)\end{array}$ & $\begin{array}{c}\text { СФ-СДО } \\
(n=5, P=0.95)\end{array}$ & $\begin{array}{c}\text { Тест-метод } \\
(n=25)\end{array}$ \\
\hline Енисей & \multirow{2}{*}{ 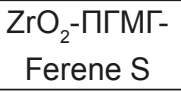 } & $0.068 \pm 0.002$ & $0.072 \pm 0.004$ & $0.075(0.05-0.10)^{*}$ \\
\hline Чулым & & $0.262 \pm 0.008$ & $0.27 \pm 0.01$ & $0.3(0.2-0.4)^{*}$ \\
\hline Базаиха & \multirow{2}{*}{ 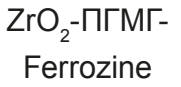 } & $0.036 \pm 0.001$ & $0.035 \pm 0.002$ & $0.037(0.025-0.05)^{*}$ \\
\hline Кача & & $0.208 \pm 0.005$ & $0.18 \pm 0.02$ & $0.15(0.1-0.2)^{*}$ \\
\hline
\end{tabular}

Примечание: * - интервал разброса результатов определения, мг/л. 
реном С на поверхности сорбентов использовано и при разработке тест-методик визуального определения железа(II) с использованием цветовых шкал.

Методика тест-определения. Для создания цветовой шкалы в ряд градуированных пробирок ёмкостью 20 мл вводят от 0.1 до 4 мкг железа(II) в виде раствора в $0.1 \mathrm{M} \mathrm{H}_{2} \mathrm{SO}_{4}, 1$ мл $0.1 \mathrm{M} \mathrm{раство-}$ ра солянокислого гидроксиламина, $\mathrm{NaOH}$ до $\mathrm{pH}$ $=3$, деионизованную воду до объема 10 мл. Вносят 0.1 г сорбента и интенсивно перемешивают 20 мин. Растворы отделяют от сорбентов декантацией, сорбенты переносят последовательно в ячейки фрторопластовой пластины с увеличением концентрации металла (цветовая шкала). В ячейку отдельной пластины вносят сорбент с неизвестной концентрацией железа(II). Излишки воды убирают с помощью фильтровальной бумаги. Сорбент с неизвестной концентрацией железа(II) перемещают вдоль цветовой шкалы, подбирая соответствие окраски сорбента. Цветовая шкала на основе $\mathrm{ZrO}_{2}$-ПГМГ-Ferrozine после высыхания сорбентов не претерпевает изменений и устойчива в течение длительного времени (более 3 месяцев). Шкала на основе $\mathrm{ZrO}_{2}$-ПГМГ-Ferene S претерпевает изменения: в течение суток сорбенты без или с низким содержанием железа(II) приобретают желтую окраску в результате окисления свободного реагента кислородом воздуха.

Тест-определение железа(II) можно проводить по окраске влажных или сухих сорбентов. Использование влажных образцов для тест-определения железа(II) предпочтительнее, поскольку сухие образцы имеют более слабую окраску.
На рис. 4 приведена фотография цветовых шкал для тест-определения железа(II) с использованием сорбентов с функциональными группами фреррозина и фререна С. Диапазон концентраций визуального определения железа(II) составляет от 0.1 до 4.0 мкг $\mathrm{Fe}(\mathrm{II})$ на 0.1 г сорбента, что при сорбции из 10 мл соответствует концентрации железа(II) в растворе 0.01-0.4 мг/л. Тест-методика использована при определении общего содержания железа в виде железа(II) в речных водах. Разработанная тест-методика позволяет проводить определение железа в водах при его концентрации более 0.01 мг/л. Средние значения и интервалы разброса результатов тест-определения общего содержания железа в природных водах, рассчитанные в соответствии с рекомендациями [18], приведены в табл. 2.

\section{ЛИТЕРАТУРА}

1. Analytical measurements in aquatic environments. Ed. by Namiensnik J., Szefer P. CRC Press, 2010. 503 p.

2. Марченко 3., Бальцежак М. Методы спектрофотометрии в УФ и видимой областях в неорганическом анализе: пер. с польского А.В. Гармаша. М.: БИНОМ, 2007. 711 с. 3. Haghighi B., Safavi A. Simultaneous flow injction determination of iron(II) and iron(III) with opto-electrochemical detection // Anal. Chim. Acta. 1997. V. 354. P. 43-50.

4. Mulaudzi L.V., van Staden J.F., Stefan R.I. On-line determination of iron(II) and iron(III) using a spectrophotometric sequential injection system // Anal. Chim. Acta. 2002. V. 467. P. 35-49.

5. Ермоленко Ю.В., Гридина Н.Н., Соколовская А.П. Химико-аналитическая система Fe(III) - тайрон - хитозан в спектрофотометрии железа // Успехи в химии и химической технологии. 2011. Т. 25, № 2. С. 50-55.

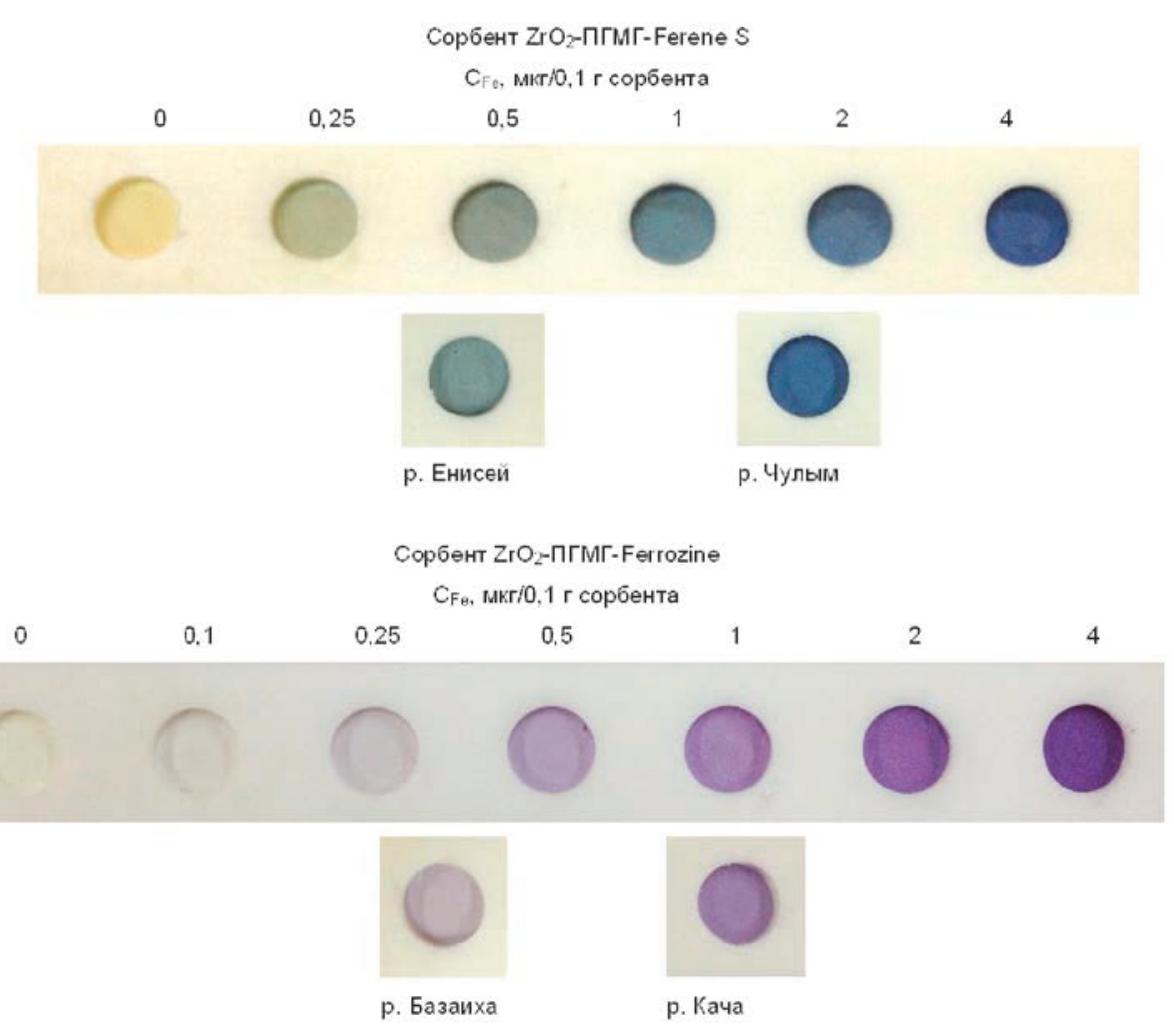

Рис. 4. Результаты тест-определения общего содержания железа в природных водах с использованием цветовых шкал на основе сорбентов $\mathrm{ZrO}_{2}$-ПГМГ-Ferrozine и $\mathrm{ZrO}_{2}$-ПГМГ-Ferene S: 0.1 г сорбента; $\mathrm{pH}=3 ; \mathrm{V}=10$ мл; $0.01 \mathrm{M} \mathrm{NH}_{2} \mathrm{OH}$ 
6. Zhenpu W., Cheng K.L. Spectrophotometric Determination of Iron with 1,10-phenanthroline in the Presence of Copper // Microchimica Acta. 1982. II. P. 115-124.

7. Van Staden J.F., Naidoo E.B. Determination of total iron as Fe(II) in multivitamins, haematinics and natural waters using a sequential injection system // South African Journal of Chemistry. 2000. V. 53, № 3. P. 191-205.

8. Jankiewicz B., Ptaszynski B., Turek A. Spectrophotometric Determination of Iron(II) in the Soil of Selected Allotment gardens in Lodz // Polish Journal of Environmental Studies. 2002. V. 11, № 6. P. 745-749.

9. Fresenius W., Schneider W. For the determination of iron(II) and total iron with 2,2'-dipyridyl in mineral waters. Reduction of iron(III) with ascorbic acid // Z. analyt. Chem. 1976. V. 209. P. 340-341.

10. Limiting reactants in chemical analysis: influences of metals and ligands on calibration curves and formation constants for selected iron-ligand chelates / M. Stauffer [et al.] // Stoichiometry and Research - The Impotance of Quantity in Biomedicine. 2012. P. 311-334.

11. Tsurubou S., Sakai T. High-sensitivity extraction - Spectrophotometric determination of iron with 3-(2-pyridyl)-5,6-diphenyl-1,2,4-triazine and tetrabromophenolphthalein ethyl ester // The Analyst. 1984. V. 109. P. 1397-1399.
12. Spectrophotometric determination of iron(II) after separation by adsorption of its complex with 3-(4-phenyl-2-pyridyl)-5,6diphenyl-1,2,4-triazine and tetraphenylborate on microcrystalline naphthalene / T. Nagahiro [et al.] // Talanta. 1985. V. 31, № 12. P. 1112-1114.

13. Organic solvent-soluble membrane filters for the preconcentration and spectrophotometric determination of iron(II) traces in water with Ferrozine / Ying Chen [et al.] // Fresenius J. Anal. Chem. 1999. V. 363. P. 119-120.

14. Сорбционное концентрирование микрокомпонентов из растворов / Ю.А. Золотов [и др.]. М.: Наука, 2007. 320 с. 15. Химия привитых поверхностных соединений / Г.В. Лисичкин [и др.] М.: Физматлит, 2003. 592 с.

16. Лосев В.Н., Дидух С.Л., Трофимчук А.К. Сорбционнофотометрическое определение железа с использованием сорбентов на основе неорганических оксидов с функциональными группами 4,7-дифенил-1,10-френантролина // Известия вузов. Химия и химическая технология. 2009. T.52, № 7. С. 32-36.

17. Шварценбах Г., Флашка Г. Комплексонометрическое титрование. М.: Химия, 1970. 360 с.

18. РешетнякЕ.А., Холина Ю.В., Шевченко В.Н. Построение цветовых шкал для визуальной колориметрии. Представление результатов анализа // Методы и объекты химического анализа. 2011. Т. 6, № 4. С. 188-197.

\title{
SORPTION-PHOTOMETRIC AND TEST - DETERMINATION OF TOTAL IRON IN NATURAL WATERS USING ZIRCONIUM OXIDE BASED SORBENTS, MODIFIED WITH POLYHEXAMETHYLENE GUANIDINE FERROZINE AND FERENE S
}

\author{
S.L. Didukh, A.N. Mukhina, V.N. Losev \\ Research Engineering Centre 'Kristall' of Siberian Federal University \\ pr. Svobodnyi, 79, Krasnoiarsk, 660041, RussianFederation
}

\begin{abstract}
The zirconium oxide based sorbents were prepared by modifying polyhexamethylene guanidine, Ferrozine or Ferene S. Optimal conditions were found for modifying the zirconium oxide by Ferrozine and Ferene $S$. The sorption capacity of the sorbents is $25 \mu \mathrm{M} / \mathrm{g}$ for Ferrozine and $5 \mu \mathrm{M} / \mathrm{g}$ for Feren S. The sorbents quantitatively extract the iron(II) from solutions of $\mathrm{pH} 2.5-7.0$. Intensively colored iron(II) complexes are formed on the sorbents surface during sorption from solutions of $\mathrm{pH} 2.5$ -5.0 during $20 \mathrm{~min}$. The diffuse reflectance spectra have maxima at 560 and $600 \mathrm{~nm}$ for the sorbents with the functional groups of Ferrozine and Ferene $S$, respectively. This effect was suggested for development of procedures of sorption-photometric and visual test determination of iron(II). The calibration curves were linear over the range $0.1-4.0 \mu \mathrm{g}$ per $0.1 \mathrm{~g}$ of the sorbent. The limit of detection sorptionphotometric determination of iron (II) calculated by the 3s-criterion is $0.006 \mu \mathrm{g} / 0.1 \mathrm{~g}$ and $0.015 \mu \mathrm{g} / 0.1 \mathrm{~g}$ for sorbents with functional groups of Ferrozine and Ferene $S$, respectively. The proposed method was used for determination of total iron in natural waters. The results of sorption-photometric determination of total iron were confirmed by the results of atomic-emission method with inductively coupled plasma.

Keywords: Adsorption, modified zirconium oxide, Ferene S, Ferrozine, Iron(II), Diffuse reflectance spectroscopy, test-systems.
\end{abstract}

\section{REFERENCES}

1. Analytical measurements in aquatic environments. Ed. by Namiensnik J., Szefer P. CRC Press, 2010. 503 p.

2. Marchenko Z., Bal'tsezhak M. Metody spectrofotometrii $v$ UF $i$ vidimoi oblastiakh $v$ neorganicheskom analize [Spectrophotometric methods in UV and VIS ranges in inorganic analysis]. Moscow, Binom, 2007. 711 p. (in Russian)

3. Haghighi B., Safavi A. Simultaneous flow injction determination of iron(II) and iron(III) with opto-electrochemical detection. Anal. Chim. Acta, 1997, vol. 354, pp. 43-50. doi: 10.1016/S0003-2670(97)00436-4.

4. Mulaudzi L.V., van Staden J.F., Stefan R.I. On-line determination of iron(II) and iron(III) using a spectrophotometric sequential injection system. Anal. Chim. Acta, 2002, vol. 467, pp. 35-49. doi: 10.1016/S0003-2670(02)00128-9.

5. Ermolenko lu.V., Gridina N.N., Sokolovskaia A.P. [Chemical-analytical system Fe (III) - tyrone - chitosan for spectrophotometry determination of iron]. Uspekhi $v$ khimii $i$ 
khimicheskoi tekhnologii [Advances in chemistry and chemical technology], 2011, vol. 25, no. 2, pp. 50-55 (in Russian). 6. Zhenpu Wang, Cheng K.L. Spectrophotometric Determination of Iron with 1,10-phenanthroline in the Presence of Copper. Microchimica Acta, 1982, II, pp. 115-124. doi: 10.1007/BF01206697 7. Van Staden J.F., Naidoo E.B. Determination of total iron as $\mathrm{Fe}(\mathrm{II})$ in multivitamins, haematinics and natural waters using a sequential injection system. South African Journal of Chemistry, 2000, vol. 53, no. 3, pp. 191-205.

8. Jankiewicz B., Ptaszynski B., Turek A. Spectrophotometric Determination of Iron(II) in the Soil of Selected Allotment gardens in Lodz. Polish Journal of Environmental Studie, 2002, vol. 11, no. 6, pp. 745-749.

9. Fresenius W., Schneider W. For the determination of iron(II) and total iron with 2,2'-dipyridyl in mineral waters. Reduction of iron(III) with ascorbic acid. Z. analyt. Chem, 1976, vol. 209, pp. 340-341.

10. Stauffer M.T., Weller W.E., Kubas K.R., Casoni K.A. Limiting reactants in chemical analysis: influences of metals and ligands on calibration curves and formation constants for selected iron-ligand chelates. Stoichiometry and ResearchThe Impotance of Quantity in Biomedicine, 2012, pp. 311-334. 11. Tsurubou S., Sakai T. High-sensitivity extraction - Spectrophotometric determination of iron with 3-(2-pyridyl)-5,6-diphenyl-1,2,4-triazine and tetrabromophenolphthalein ethyl ester. The Analyst, 1984, vol. 109, pp. 1397-1399. doi: 10.1039/ AN9840901397.

12. Nagahiro T., Uesugi K., Mehra M.C., Satake M. Spectrophotometric determination of iron(II) after separation by adsorption of its complex with 3-(4-phenyl-2-pyridyl)-5,6-di- phenyl-1,2,4-triazine and tetraphenylborate on microcrystalline naphthalene. Talanta, 1985, vol. 31, no. 12, pp. 1112-1114. doi: 10.1016/0039-9140(84)80259-3.

13. Ying Chen, Chang-Ming Ding, Tian-Ze Zhou, Da-Yong Qi. Organic solvent-soluble membrane filters for the preconcentration and spectrophotometric determination of iron(II) traces in water with Ferrozine. Fresenius J. Anal. Chem, 1999, vol. 363, pp. 119-120. doi: 10.1007/s002160051152.

14. Zolotov lu.A., Tsizin G.I., Dmitrienko S.G., Morosanova E.I. Sorbtsionnoe kontsentrirovanie mikrokomponentov iz rastvorov [Sorption concentration of micro components from solutions]. Moscow, Science, 2007. 320 p. (in Russian). 15. Lisichkin G.V., Fadeev A.Y., Serdan A.A., Mingalyov P.G., Nesterenko P.N., Furman D.B. Khimiia privitykh poverkhnostnykh soedinenii [Chemistry of Surface Grafted Compounds]. Moscow, Fizmatlit, 2003. 592 p. (in Russian). 16. Losev V.N., Didukh S.L., Trofimchuk A.K. [Sorption photometric determination of iron using sorbents on the basis of inorganic oxides having functional groups of 4,7-diphenyl-1,10-phenanthroline]. Izvestiia vyzov. Khimiia i khimicheskaia technologiia [Chemistry and chemical technology], 2009, vol. 52, no. 7, pp. 32-36 (in Russian).

17. Shvartsenbach G. Flashka G. Kompleksonometricheskoe titrovanie [Complexometric Titration]. Moscow, Chemistry, 1970.360 p. (in Russian).

18. Reshetniak E.A., Kholina Yu.V., Shevchenko V.N. [The color scales constraction for visual colorimetry. Representation of analysis results]. Metody i ob"ekty khimicheskogo analiza [Methods and objects of chemical analysis], 2011, vol. 6, no 4, pp. 188-197 (in Russian). 